\title{
Níveis de concentrado na dieta de bovinos Nelore de três condições sexuais: consumo, digestibilidades total e parcial, produção microbiana e parâmetros ruminais ${ }^{1}$
}

\section{Robson Magno Liberal Véras ${ }^{2 *}$, Sebastião de Campos Valadares Filho ${ }^{3}$, José Augusto Gomes Azevêdo ${ }^{4}$, Edenio Detmann ${ }^{3}$, Pedro Veiga Rodrigues Paulino², Analívia Martins Barbosa ${ }^{5}$, Marcos Inácio Marcondes ${ }^{2}$}

\footnotetext{
1 Projeto financiado pelo CNPq.

2 Programa de Pós-graduação em Zootecnia - UFV.

${ }^{3}$ Departamento de Zootecnia - Universidade Federal de Viçosa.

${ }^{4}$ Universidade Estadual de Santa Cruz - Ilhéus - BA.

5 Programa de Pós-graduação em Medicina Veterinária - UFV.
}

RESUMO - Doze bovinos Nelore de três condições sexuais (CS) - quatro fêmeas, quatro machos castrados e quatro machos não-castrados - com idade aproximada de 15 meses e peso corporal médio de 235, 249 e 239 kg, respectivamente, foram distribuídos em delineamento inteiramente casualizado, em esquema fatorial $2 \times 3$, composto de dois níveis de concentrado (25 ou 50\%) e três CS, objetivando-se estudar o consumo, as digestibilidades total e parcial dos nutrientes, a produção microbiana e os parâmetros ruminais. As coletas de líquido ruminal, para determinação do pH e da concentração de amônia, foram realizadas imediatamente antes do fornecimento da dieta e 2, 4 e 6 horas após a alimentação. Não houve interação significativa de níveis de concentrado e CS para nenhum dos consumos observados. Os consumos de MS, MO, EE, PB, CNF e NDT, em kg/dia, e de MS em \% do PC ou em $\mathrm{g} / \mathrm{kg}^{0,75}$, não foram influenciados pelos níveis de concentrado ou pela condição sexual. Não houve interação de níveis de concentrados $\times$ CS para as digestibilidades totais e parciais dos nutrientes, com exceção do EE. O aumento do nível de concentrado reduziu a digestibilidade da FDN. Os teores médios de N nas bactérias variaram de 7,39 a 6,91\%. O fluxo de nutrientes e a eficiência microbiana expressa de diferentes formas, com exceção de gNmic/kgMODR, não foram influenciados pelos níveis de concentrados ou pela condição sexual. A concentração de $\mathrm{NH}_{3}$ máxima de $14,55 \mathrm{mg} / \mathrm{dL}$ foi estimada 1,83 hora após a alimentação. O aumento dos níveis de concentrado na dieta não resultou em respostas positivas para os consumos, as digestibilidades parciais e totais da maioria dos nutrientes e a produção microbiana.

Palavras-chave: amônia ruminal, fêmea, macho castrado, macho não-castrado, pH ruminal

\section{Increasing dietary concentrate levels for Nellore of three sexual categories: intake, partial and total tract digestibility, microbial protein synthesis and ruminal metabolism}

\begin{abstract}
Twelve Nellore of three sexual categories (four heifers, four bulls and four steers) averaging 15 months of age and body weight of 235, 249, and $239 \mathrm{~kg}$, respectively, were assigned to a completely randomized design with a $2 \times 3$ factorial arrangement (two levels of concentrate -25 or $50 \%$ and three sexual categories) to evaluate intake, partial and total digestibility of nutrients, microbial protein synthesis and ruminal metabolism. The collection of ruminal fluid was done before and at 2, 4, and 6 hours post-feeding to determine $\mathrm{pH}$ and ammonia concentration. With the exception of EE, no other significant effect of concentrate levels and sexual categories was observed on intake and partial or total tract digestibility of nutrients. The intakes of DM, OM, EE, CP, NFC, and TDN (kg/day) and DM (\% BW or g/kg.75) were affected neither by the concentrate levels nor by sexual category. Increasing dietary concentrate levels decreased NDF digestibility. Average bacterial $\mathrm{N}$ contents ranged from 6.91 to 7.39. No significant effect of concentrate levels and sexual category was observed on duodenal flow of nutrients and microbial efficiency excepted when expressed as gNmic/kgOMDR. Maximum ruminal $\mathrm{NH}_{3}$ concentration $(14.55 \mathrm{mg} / \mathrm{dL})$ was estimated at 1.83 hours after-feeding. It was concluded that increasing dietary concentrate levels did not affect intake, partial and total tract digestibility of most nutrients and microbial protein synthesis.
\end{abstract}

Key Words: bull, heifer, ruminal ammonia, ruminal $\mathrm{pH}$, steer

Este artigo foi recebido em 4/4/2006 e aprovado em 29/10/2007.

Correspondências devem ser enviadas para robson.veras@ufra.edu.br

*Endereço atual: Universidade Federal Rural da Amazônia - Parauapebas - PA. 


\section{Introdução}

O rebanho bovino nacional é composto aproximadamente por 165 milhões de cabeças, dos quais 33,5 milhões são novilhas e 31,5 milhões, novilhos de 1 a 3 anos (Anualpec, 2005). Os animais em confinamento e semiconfinamento somam, aproximadamente, 5 milhões de cabeças, com perspectivas de crescimento neste contingente e, por conseguinte, na utilização de concentrados para maximizar os ganhos e reduzir o tempo de permanência dos animais nessas condições. Apesar de a arroba produzida ser mais cara que aquela produzida a pasto, o importante para o pecuarista é o custo médio por arroba produzida na fazenda e o seu desfrute, e não somente o custo de uma fase, como é a engorda de bovinos em confinamento (Lacôrte, 2002).

O controle da ingestão de alimento é o resultado de vários mecanismos inter-relacionados, integrados na resposta final de alimentação. A ingestão de MS (IMS) é controlada por fatores fisiológicos, físicos e psicogênicos (Van Soest, 1994; Valadares, 1997). Dias et al. (2000) afirmaram que a dominância de um mecanismo de controle de consumo sobre o outro pode estar associada à qualidade da dieta, em conteúdo energético e digestibilidade, mas sua correlação com o consumo pode ser positiva ou negativa. Quando fornecidas dietas de alta digestibilidade, o consumo é menor quanto mais digestível é o alimento, pois o animal terá suas exigências energéticas atendidas com menores níveis de consumo. Por outro lado, o consumo de dietas de baixa qualidade será maior quanto menor a digestibilidade do alimento (Van Soest, 1994).

A otimização da fermentação ruminal, juntamente com a maximização da eficiência de síntese de proteína microbiana, tem sido estudada em vários países. De acordo com o NRC (1996), 50 a 100\% da proteína metabolizável exigida pelo bovino de corte pode ser atendida pela proteína de origem microbiana. Segundo Kozloski (2002), o suprimento de proteína para o duodeno consiste da proteína microbiana sintetizada no rúmen, proteína dietética não-degradada e proteína endógena. Entretanto, a produção e eficiência microbiana também são afetadas pela quantidade de MO fermentada no rúmen; uma das formas de manipular esta quantidade seria pelo ajuste da relação volumoso:concentrado das dietas (Cecava et al., 1991).

Ainda como recurso de avaliação dos parâmetros ruminais, destaca-se a determinação da concentração de amônia ruminal, que permite avaliar o balanceamento de proteína da dieta, de modo que altas concentrações de amônia estejam associadas ao excesso de proteína degradada no rúmen e/ou à baixa concentração de carboidratos fermentáveis (Ribeiro et al., 2001; Cavalcante et al., 2005a, b). Muitos autores defendem a existência de concentrações mínimas de $\mathrm{N}-\mathrm{NH}_{3}$ para que não sejam limitadas a fermentação e degradação da fibra, porém, não há consenso sobre um valor comum. Satter \& Slyter (1974) e Mehrez et al. (1977), citados por Franco et al. (2004), recomendam de 2 a $5 \mathrm{mg}$ de $\mathrm{N}-\mathrm{NH}_{3} / 100 \mathrm{~mL}$ e de 19 a $23 \mathrm{mg}$ de $\mathrm{N}-\mathrm{NH}_{3} / 100 \mathrm{~mL}$ de líquido ruminal, respectivamente.

Os objetivos nesta pesquisa foram avaliar possíveis diferenças nos consumos e nas digestibilidades total e parcial dos nutrientes, na produção microbiana e nos parâmetros ruminais de bovinos Nelore de três condições sexuais (fêmeas, machos castrados e machos nãocastrados) alimentados com dietas com dois níveis de concentrado.

\section{Material e Métodos}

O experimento foi conduzido nos Laboratórios de Animais e de Nutrição Animal do Departamento de Zootecnia do Centro de Ciências Agrárias da Universidade Federal de Viçosa, em Viçosa, Minas Gerais, localizada na Zona da Mata de Minas Gerais, com 20045'20" de latitude sul, $45^{\circ} 52^{\prime} 40^{\prime \prime}$ de longitude oeste de Greenwich e altitude de $657 \mathrm{~m}$. A fase de campo foi realizada entre maio e outubro de 2004. A temperatura média, a precipitação pluviométrica e a umidade relativa do ar em 2004 foram de $19,5^{\circ} \mathrm{C}$, $1.761 \mathrm{~mm}$ e 82,6\%, respectivamente (UFV, 2006).

Foram utilizados 12 bovinos Nelore, quatro de cada condição sexual (CS): fêmeas, machos castrados e machos não-castrados, com idade aproximada de 15 meses e peso corporal (PC) médio de 235, 249 e 239 kg, respectivamente. Todos os animais foram fistulados no rúmen e no duodeno e alojados em baias individuais cobertas $\left(9 \mathrm{~m}^{2}\right)$, com piso de concreto revestido de borracha, providas de comedouros e de bebedouros individuais. Os animais foram distribuídos em delineamento inteiramente casualizado, em esquema fatorial $2 \times 3$, composto de dois níveis de concentrado (25 ou 50\%) e três condições sexuais, com quatro repetições.

O experimento foi conduzido em dois períodos, cada um com duração de 15 dias - nove para adaptação às dietas e seis para coletas. As dietas foram constituídas de silagem de milho e concentrado nas proporções de 25 ou $50 \%$, com base na MS, e balanceadas de acordo com o NRC (1996) para conter aproximadamente $12 \%$ de PB (Tabelas 1 e 2). Os concentrados foram formulados à base de milho, uréia, farelo de algodão com 38\% de PB e mistura mineral.

Nos períodos 1 e 2, foram oferecidas a todos os animais dietas com 25 e $50 \%$ de concentrado na base da MS, 
respectivamente. A alimentação foi fornecida duas vezes ao dia, sempre às 8 e 16 h, na forma de ração completa, à vontade, permitindo-se sobras de, no máximo, 5 a 10\%.

Diariamente, foram registradas as quantidades dos alimentos fornecidos e das sobras de cada animal para estimativa do consumo. Durante o período experimental, foram realizadas amostragens das dietas e sobras; para as sobras diárias de cada animal, foi feita uma amostra composta por período. Todas as amostras foram acondicionadas em sacos plásticos e congeladas para análises posteriores.

Para avaliação do $\mathrm{pH}$ e da concentração $\mathrm{N}-\mathrm{NH}_{3}$ ruminal, realizaram-se, no 15 을 dia do período experimental, coletas de líquido ruminal imediatamente antes do fornecimento da dieta e 2, 4 e 6 horas após o fornecimento da dieta $(8,10,12$ e $14 \mathrm{~h})$. As amostras foram coletadas na região de interface líquido/sólido do ambiente ruminal e filtradas em camada tripla de gaze, determinando-se o $\mathrm{pH}$. Uma alíquota de $40 \mathrm{~mL}$, adicionada de $1 \mathrm{~mL}$ de ácido clorídrico (1:1), foi acondicionada em frasco de plástico, que foi identificado e congelado a $-15^{\circ} \mathrm{C}$ para posterior quantificação da concentração de $\mathrm{N}-\mathrm{NH}_{3}$.

No 15으 dia do período experimental, realizou-se também a coleta de líquido ruminal com o objetivo de isolar micror-

Tabela 1 - Proporção dos ingredientes nos concentrados (\% matéria natural)

\begin{tabular}{lrr}
\hline & \multicolumn{2}{c}{ Nível de concentrado (\%) } \\
\cline { 2 - 3 } Item & \multicolumn{1}{c}{25} & \multicolumn{1}{c}{50} \\
\hline Fubá de milho & 58,90 & 83,20 \\
Farelo de algodão 38\% & 33,90 & 13,20 \\
Uréia/Sulfato de amônia & 3,00 & 1,50 \\
Cloreto de sódio & 1,10 & 0,55 \\
Mistura mineral & 1,10 & 0,55 \\
Calcário & 2,00 & 1,00 \\
\hline
\end{tabular}

* Conteúdo por kg do produto: Ca - $240 \mathrm{~g} ; \mathrm{P}-174 \mathrm{~g} ; \mathrm{Co}-100 \mathrm{mg} ; \mathrm{Cu}$ $1.250 \mathrm{mg}, \mathrm{Fe}-1.795 \mathrm{mg}, \mathrm{F}$ (max.) - $1.740 \mathrm{mg} ; \mathrm{I}-90 \mathrm{mg}$; Mn - $2.000 \mathrm{mg}$; $\mathrm{Zn}-5.270 \mathrm{mg}$; Se - $15 \mathrm{mg}$; veículo q.s.p. $-1.000 \mathrm{~g}$. ganismos ruminais 6 horas após o fornecimento da dieta, conforme técnica descrita por Cecava et al. (1990). As amostras foram acondicionadas em frascos de polietileno e congeladas a $-15^{\circ} \mathrm{C}$, após adição de formaldeído (PA), na proporção de $10 \mathrm{~mL} / \mathrm{L}$, como agente conservante.

A produção de MS fecal e os fluxos de MS nos compartimentos do trato gastrintestinal foram estimados com a utilização de óxido crômico como indicador, administrado em dose única diária de $15 \mathrm{~g}$, via fístula ruminal, do $3 \underline{0}$ ao $15 \underline{0}$ dia de cada período experimental, sempre às $12 \mathrm{~h}$. As coletas de fezes e digestas de duodeno foram feitas uma vez ao dia, simultaneamente, em intervalos de 26 horas, com início às 8 h do 10 o dia e término às 18 h do $15^{0}$ dia de cada período experimental. As amostras foram armazenadas em sacos plásticos a $-15^{\circ} \mathrm{C}$ e, posteriormente, submetidas à pré-secagem em estufa de ventilação forçada a $65^{\circ} \mathrm{C}$, por 72 horas, e processadas em moinhos com peneira com malha de $1 \mathrm{~mm}$. Das amostras diárias, foi retirada uma alíquota para formar as compostas por animal em cada período, que foram acondicionadas em recipientes plásticos para posterior análise.

A quantificação da biomassa microbiana nas amostras do rúmen e duodeno foi feita utilizando-se as bases purinas como indicadores (Ushida et al., 1985). A eficiência de síntese microbiana foi expressa em g de $\mathrm{N}$ microbiano por kg de $\mathrm{MO}$ aparente degradada no rúmen (MODR) e de MO verdadeiramente degradada no rúmen (MOVDR) e PB microbiana por kg de NDT.

As análises de MS, MO, PB, EE e lignina foram realizadas conforme procedimento descrito por Silva \& Queiroz (2002). As determinações de FDN e FDA foram realizadas de acordo com o método proposto por Van Soest \& Robertson (1985) utilizando-se o extrator ANKON ${ }^{200}$ (Ankom Technology Corp., Fairport, NY, USA). Face à presença de uréia nas dietas, os CNF dos concentrados foram calculados segundo Hall (2000), em que $\% C N F=100-[(\% P B-\% P B$

Tabela 2 - Composição química das dietas experimentais, com base na MS

\begin{tabular}{|c|c|c|c|c|c|c|}
\hline Item & \multicolumn{2}{|c|}{ Silagem de milho } & \multicolumn{2}{|c|}{ Concentrado (\%) } & \multicolumn{2}{|c|}{ Dieta total (\%) } \\
\hline MS (\%) & 23,29 & 27,58 & 89,28 & 88,45 & 39,78 & 58,01 \\
\hline $\mathrm{PB}^{1}$ & 6,85 & 7,23 & 25,10 & 15,27 & 11,42 & 11,25 \\
\hline $\mathrm{EE}^{1}$ & 2,94 & 2,94 & 2,76 & 3,49 & 2,89 & 3,20 \\
\hline $\mathrm{FDN}^{1}$ & 48,79 & 51,35 & 19,48 & 13,57 & 41,46 & 32,46 \\
\hline $\mathrm{LIG}^{1}$ & 4,26 & 4,56 & 3,91 & 2,18 & 4,17 & 3,37 \\
\hline NDT & - & - & - & - & 62,89 & 60,25 \\
\hline
\end{tabular}

$\mathrm{P} 1=$ período $1 ; \mathrm{P} 2$ = período 2.

$1 \%$ da MS. 
derivada da uréia + \% de uréia) + \%EE + \%FDN + \%cinzas].

Os teores de $\mathrm{N}$ amoniacal no líquido ruminal foram avaliados pelo sistema micro-Kjeldahl, sem digestão ácida da amostra, utilizando-se como base para destilação o hidróxido de potássio (2N), após centrifugação da amostra a $1.000 \mathrm{x}$ g por 15 minutos.

As amostras de fezes e digesta duodenal foram submetidas à análise de teor de cromo em espectrofotômetro de absorção atômica, conforme método descrito por Willians et al. (1962).

Os teores de NDT foram determinados conforme a equação proposta pelo NRC (2001): $N D T=P B d+2,25 E E d$ $+F D N d+C N F d$, em que $d$ é o respectivo nutriente digestível.

$\mathrm{O}$ experimento foi analisado segundo delineamento inteiramente casualizado, em esquema fatorial $3 \times 2$ (três CS e dois níveis de concentrado). As avaliações das variáveis pH e concentração ruminal de amônia foram feitas mediante subdivisão de parcelas, em função do tempo de avaliação (split-plot no tempo). Os resultados foram avaliados utilizando-se o programa SAS (SAS, 1999), adotando-se 0,05 como nível crítico de probabilidade para o erro tipo I. As médias foram comparadas pelo teste Tukey.

\section{Resultados e Discussão}

Não houve interação $(P>0,05)$ níveis de concentrado $\times$ CS para os consumos de todos os nutrientes (Tabela 3 ). Também não houve efeito $(\mathrm{P}>0,05)$ dos níveis de concentrado e das condições sexuais sobre os consumos de MS, MO, EE, $\mathrm{PB}, \mathrm{CNF}$ e NDT, em kg/dia, e sobre o consumo de MS, em $\%$ do PC e g/ $\mathrm{kg}^{0,75}$.

Estudando animais de mesmas condições sexuais alimentados com os mesmos níveis de concentrado, Barbosa (2005) também não observou diferença nos consumos de MS e MO. Do mesmo modo, Cardoso et al. (2000), ao estudarem cinco níveis de concentrado adicionados ao feno de capim-coastcross, não observaram efeitos nos consumos de MS e MO expressos da mesma forma.

Diferentemente, Ladeira et al. (1999a) e Dias et al. (2000) observaram aumento linear no consumo de MS, independentemente da forma como foi expresso (kg/dia, \%PC ou $\mathrm{g} / \mathrm{kg}^{0,75}$ ), quando avaliaram níveis crescentes de concentrado na dieta de bovinos castrados. Segundo esses autores, o aumento no consumo de MS com o acréscimo nos níveis de concentrado nas rações pode ter ocorrido em razão da menor quantidade de FDN ingerida.

Os resultados obtidos neste estudo foram inferiores aos encontrados por Ítavo et al. (2002), que, avaliando os consumos e as digestibilidades de nutrientes em bovinos Nelore nas fases de cria e terminação alimentados com diferentes níveis de concentrado e proteína bruta, observaram comportamento quadrático para os consumos de MS, MO e PB e obtiveram, respectivamente, valores máximos de 7,$60 ; 7,23$ e $1,30 \mathrm{~kg} /$ dia com 45,94; 46,94; e 40,91\% de concentrado.

O consumo de FDN reduziu com o aumento dos níveis de concentrado nas dietas $(\mathrm{P}<0,05)$. A diminuição de 2,32 para $1,72 \mathrm{~kg} /$ dia no consumo de FDN possivelmente foi

Tabela 3 - Consumos diários de nutrientes em bovinos de três condições sexuais (CS) alimentados com dietas contendo 25 ou $50 \%$ de concentrado

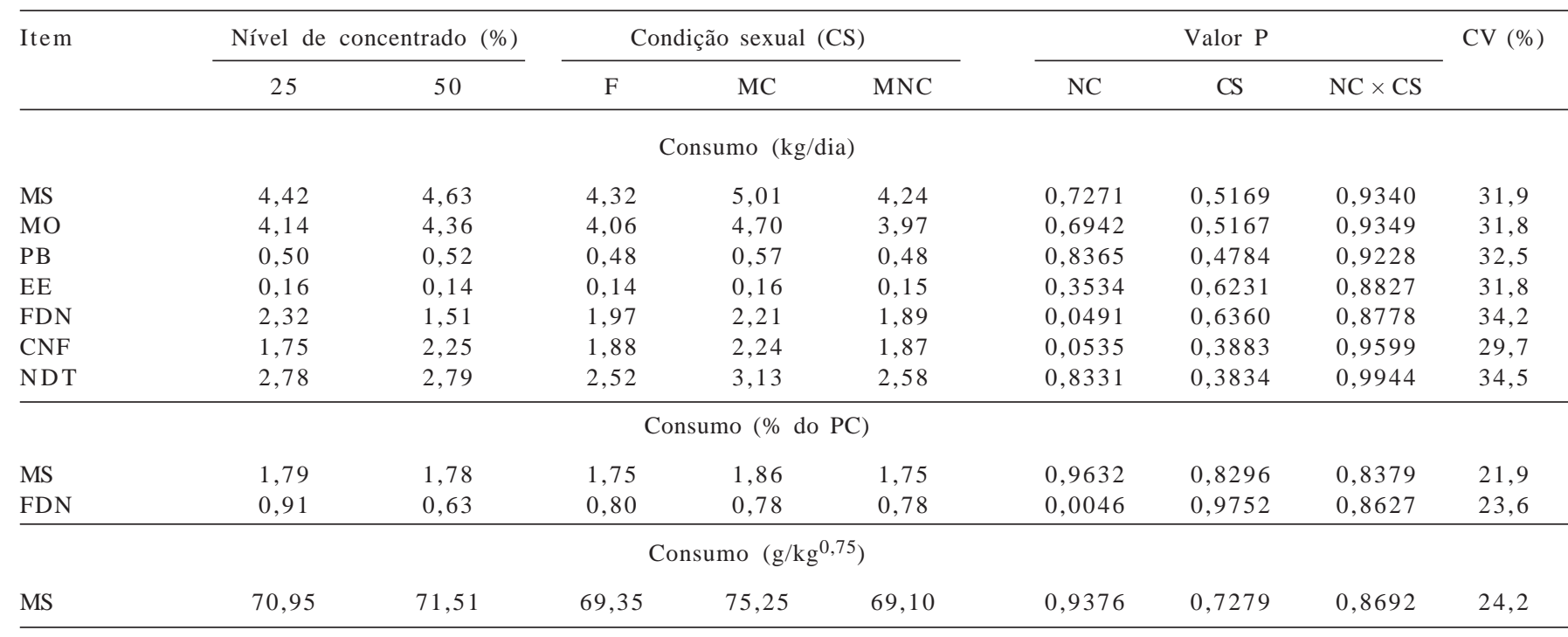

$\mathrm{NC}=25$ e $50 \%$ de concentrado na MS

$\mathrm{CS}=$ condição sexual $; \mathrm{F}=$ fêmea $; \mathrm{MC}=$ macho castrado; $\mathrm{MNC}=$ macho não-castrado

$\mathrm{P}=$ probabilidade; $\mathrm{NC}=$ nível de concentrado; $\mathrm{CS}=$ condição sexual; $\mathrm{NC}{ }^{\star} \mathrm{CS}=$ nível de concentrado $\times$ condição sexual. 
reflexo da diminuição da quantidade deste componente na dieta (Tabela 2). Quando expresso em \% do PC, ocorreu o mesmo comportamento.

Segundo Van Soest (1994), existe relação entre composição da dieta e consumo, uma vez que o consumo depende do volume estrutural e, conseqüentemente, do conteúdo da parede celular. Nesta pesquisa, foi obtido consumo de FDN de 0,67 e $0,91 \%$ do PC, valor bem abaixo de $1,2 \%$ do PC, que resulta no consumo ótimo de MS para vacas de leite, segundo Mertens (1992). A estimativa do consumo de MS a partir do teor de FDN dietético não é muito acurada, pois existe influência do tamanho da partícula, da digestibilidade e da taxa de passagem da fonte de FDN sobre o consumo (NRC, 2001).

Rennó (2003) observou consumos de MS e FDN, em \% PC, de 1,82 e 0,82, próximos aos verificados neste estudo, de 1,75 a 1,86 e 0,63 a 0,91\%, e atribuíram o baixo consumo à baixa densidade energética das dietas.

Não houve diferença significativa $(\mathrm{P}>0,05)$ no consumo de CNF, porém, o aumento numérico do consumo de CNF com a elevação do teor de concentrado na dieta pode ter sido conseqüência da redução do teor de FDN na dieta.

Os valores médios diários de consumo de MS obtidos neste trabalho para as dietas com 25 e $50 \%$ de concentrado, respectivamente, de 1,79 e 1,78\% do PC, foram considerados baixos para bovinos em crescimento, o que pode estar relacionado, em parte, ao tipo de fístula duodenal utilizado, que pode ter alterado o comportamento dos animais.
Segundo o NRC (1996) e Dias et al. (2000), existe variação nos resultados com animais fistulados, em virtude do estresse a que são submetidos.

Não houve interação $(P>0,05)$ níveis de concentrado $\times$ condição sexual para as digestibilidades totais e ruminais dos nutrientes, com exceção do EE (Tabela 4). Considerando o consumo desses nutrientes, observou-se diminuição apenas no consumo de FDN. As digestibilidades totais médias de MS e MO para o nível de $25 \%$ de concentrado foram de 57,87 e $62,65 \%$, respectivamente, superiores às observadas por Cardoso et al. (2000), de 54,90 e 57,22\%. Todavia, os valores de digestibilidade de MS e MO obtidos para o nível de $50 \%$ (59,68 e 64,35\%) foram inferiores aos 65,88 e $67,67 \%$ observados por esses autores.

O nível de concentrado na dieta influenciou o coeficiente de digestibilidade da FDN, que diminuiu $(\mathrm{P}<0,05)$ com o aumento do nível de concentrado, em razão da diminuição do $\mathrm{pH}$.

A digestibilidade aparente total dos CNF foi influenciada $(\mathrm{P}<0,05)$ pelo acréscimo de concentrado à dieta, que provocou diminuição de 93,19 para $75,60 \%$, possivelmente em decorrência do aumento do consumo deste nutriente com a maior participação do fubá de milho, rico em amido (Tabela 1), que passou de 58,90 para 83,20\%, nas dietas com 25 e 50\%, respectivamente. De acordo com Branco et al. (1999), o amido, quando utilizado em grande proporção, pode não ser completamente fermentado no rúmen e aumentar o fluxo para o duodeno. Embora grande parte deste amido

Tabela 4 - Digestibilidades total e ruminal dos nutrientes em bovinos de três condições sexuais (CS) alimentados com dietas contendo 25 ou $50 \%$ de concentrado

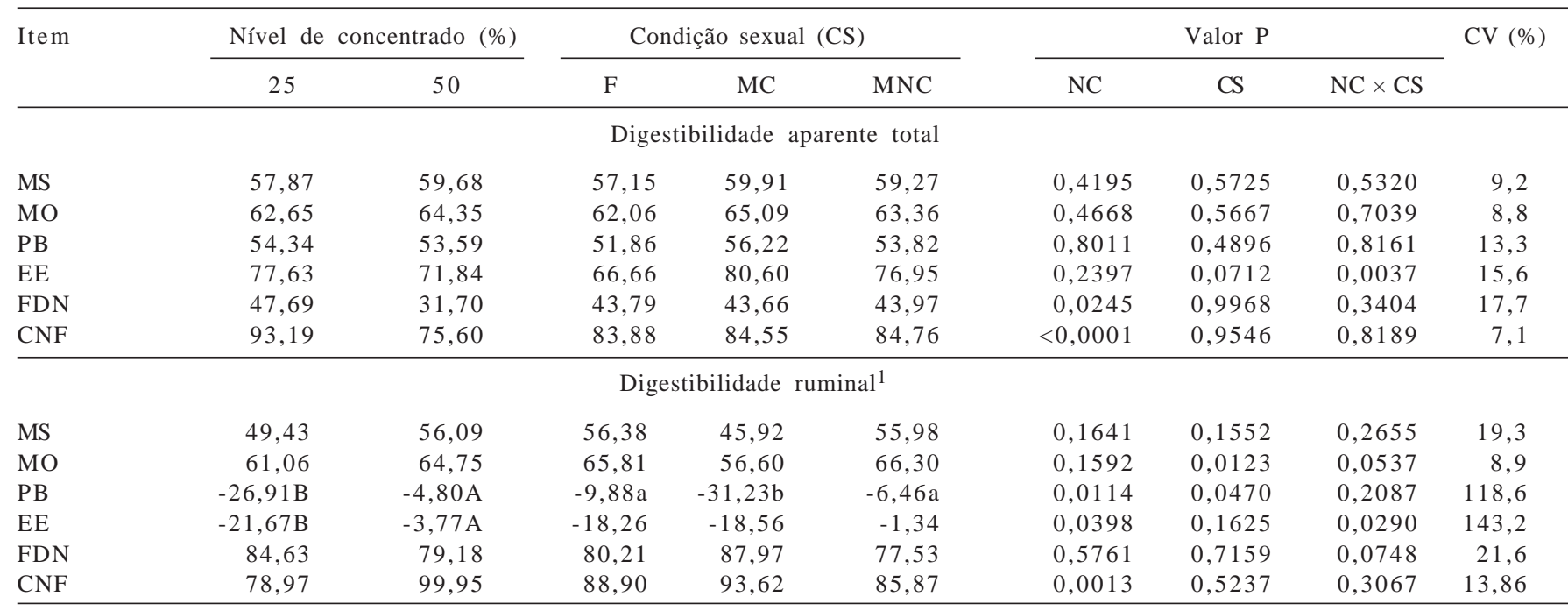

Médias, nas linhas e colunas, acompanhadas por letras maiúsculas comparam níveis de concentrado e minúsculas, condição sexual. Letras diferentes diferem $(\mathrm{P}<0,05)$ pelo teste Tukey.

${ }^{1}$ Digestibilidade calculada em \% do total digerido, com exceção de PB e EE, que foram calculados em \% da quantidade que chegou a cada local. $\mathrm{NC}=$ nível de concentrado ( 25 ou $50 \%$ na MS).

$\mathrm{CS}=$ condição sexual; $\mathrm{F}=$ fêmea; $\mathrm{MC}=$ macho castrado; $\mathrm{MNC}=$ macho não-castrado.

$\mathrm{P}=$ probabilidade; $\mathrm{NC}=$ nível de concentrado; $\mathrm{CS}=$ condição sexual; $\mathrm{NC}{ }^{\star} \mathrm{CS}=$ nível de concentrado $\times$ condição sexual. 
seja digerida no intestino, provocando aumento do consumo, a eficiência de digestão do amido, principal constituinte do CNF, reduz. De acordo com Nocek \& Russel (1988), se existir deficiência ou ineficiência de utilização da proteína, a digestibilidade desses carboidratos pode diminuir.

Não houve efeito dos níveis de concentrado e da condição sexual $(\mathrm{P}>0,05)$ sobre a digestibilidade aparente total da PB, possivelmente em razão de as dietas terem sido isoprotéicas. Esse resultado difere dos obtidos por Dias et al. (2000), que notaram aumentos lineares da digestibilidade aparente total da PB com o aumento da quantidade de concentrado. O valor médio obtido nesta pesquisa $(53,96 \%)$ foi inferior ao observado por Cardoso et al. (2000) e Chizzotti et al. (2005), de 58,29 e 63,08\%, respectivamente, e superior ao relatado por Dias et al. (2000), de 50,05\%.

A digestibilidade aparente ruminal da MS não foi influenciada ( $\mathrm{P}>0,05)$ pelos níveis de concentrado ou pela condição sexual e apresentou média de $52,76 \%$, valor inferior aos 57,48 e 54,45\% relatados, respectivamente, por Dias et al. (2000) e Cardoso et al. (2000), ambos avaliando cinco níveis de concentrado $(25,0 ; 37,5 ; 50,0 ; 62,5$ e 75,0). O valor médio de digestibilidade ruminal da FDN $(81,90 \%)$ encontra-se abaixo de alguns valores citados na literatura, pois, segundo Rennó (2003), são esperados valores acima de 90\%, em razão de a FDN ser digerida principalmente no rúmen. Valadares et al. (1997), Ladeira et al. (1999a) e Cardoso et al. (2000) relataram valores médios de 94,0; 96,4 e 95,9\%, respectivamente.

Ao avaliar a digestibilidade ruminal da $\mathrm{MO}$, nota-se que houve efeito da CS $(\mathrm{P}<0,05)$, uma vez que o menor valor foi obtido nos machos castrados. Segundo Zinn \& Owens (1983), este fato pode decorrer do aumento numérico do nível de consumo (Tabela 2) entre os machos castrados, o que, conseqüentemente, pode diminuir a MO fermentada no rúmen, como resultado da redução no tempo de retenção no rúmen, que provoca diminuição da MO prontamente fermentada no rúmen por unidade de tempo.

A digestibilidade ruminal de PB foi influenciada tanto pelos níveis de concentrado como pela condição sexual $(\mathrm{P}<0,05)$. De acordo com Mendes et al. (2005), quando há sincronia entre energia e proteína disponível ao crescimento microbiano no rúmen, espera-se que o valor da digestibilidade aparente ruminal de PB esteja o mais próximo possível de zero. Nesta pesquisa, o valor médio de digestibilidade ruminal da PB foi de -15,85\%; obtiveram-se valores negativos para todos os efeitos, provavelmente porque as dietas foram deficientes em proteína degradada no rúmen (PDR), que pode limitar o crescimento microbiano.
Mendes et al. (2005), avaliando o consumo e as digestibilidades total e parcial em novilhos em confinamento alimentados com dietas com farelo de girassol e três fontes de energia, observaram valor médio de $20,97 \%$ para a digestibilidade ruminal da PB e concluíram que, ao contrário do verificado neste estudo, houve alta degradação ruminal do farelo de girassol, principal fonte de proteína utilizada na dieta.

A digestibilidade ruminal da $\mathrm{PB}$ foi calculada como: ((Cons. de PB - Fluxo de PB no Duodeno / Cons. de PB) × 100)). Os valores negativos são indicativos de síntese microbiana, evidenciada pelo maior fluxo de PB para o duodeno, maior que o consumo. O maior valor para a dieta com $25 \%$ de concentrado (-26,91 versus $-4,80 \%$ ) comprova que a dieta com $25 \%$ de concentrado forneceu maior disponibilidade de substrato para síntese microbiana.

Neste estudo, houve aumento da digestibilidade ruminal de CNF com o acréscimo no nível de concentrado, sendo de 78,97 e 99,95\%. Leão et al. (2005), ao estudarem os consumos e as digestibilidades dos nutrientes em novilhos submetidos a três níveis de ingestão, também encontram aumento da digestão ruminal de CNF de 84,8 a 95,4\%, com amostras coletadas no omaso, e não verificaram diferença quando a coleta foi realizada no abomaso, observando-se valor médio de $78,5 \%$.

Foi observada interação $(\mathrm{P}<0,05)$ nível de concentrado $\times$ condição sexual para as digestibilidades total e ruminal do EE (Tabela 5). Avaliando a CS entre os níveis de concentrado, observa-se que as fêmeas apresentaram maior digestibilidade total do EE nas dietas com $25 \%$ de concentrado, enquanto as digestibilidades totais do EE não diferiram $(\mathrm{P}>0,05)$ entre os níveis de concentrado para machos castrados e nãocastrados.

Avaliando a condição sexual dentro de cada nível de concentrado, não se observou efeito $(\mathrm{P}>0,05)$ no nível de $25 \%$ de concentrado. No nível de $50 \%$ de concentrado, porém, a digestão total do EE foi menor $(\mathrm{P}<0,05)$ para as fêmeas.

Considerando a digestão ruminal do EE, observa-se que, comparando os níveis de concentrado, apenas a digestão dos machos castrados foi menor $(\mathrm{P}<0,05)$ para o nível de 25\% de concentrado. Avaliando a CS dentro de cada nível de concentrado, verificou-se que a digestão ruminal foi menor $(\mathrm{P}<0,05)$ nos animais machos castrados alimentados com $25 \%$ de concentrado. No nível de $50 \%$ de concentrado, a digestão ruminal foi maior $(\mathrm{P}<0,05)$ entre os machos não-castrados.

Contrariamente, Chizzotti et al. (2005) substituíram parcialmente capim-elefante por casca de algodão na dieta 
Tabela 5 - Efeito dos níveis de concentrado (NC) e da condição sexual (CS) sobre os coeficientes de digestibilidades totais (DT) e ruminais (DR) do EE

\begin{tabular}{lrrrrr}
\hline \multirow{2}{*}{ CS } & \multicolumn{2}{c}{ DT } & & \multicolumn{2}{c}{ DR } \\
& \multicolumn{2}{c}{ Nível de concentrado } & & \multicolumn{2}{c}{ Nível de concentrado } \\
\cline { 2 - 3 } \cline { 5 - 6 } & 25 & 50 & & 25 & 50 \\
\hline F & $82,36 a \mathrm{~A}$ & $50,97 \mathrm{bB}$ & & $-16,69 \mathrm{aAB}$ & $-19,82 \mathrm{aB}$ \\
MC & $74,04 \mathrm{a}$ & $87,16 \mathrm{aA}$ & & $-44,76 \mathrm{bB}$ & $7,64 \mathrm{aAB}$ \\
MNC & $76,50 \mathrm{aA}$ & $77,40 \mathrm{aA}$ & & $-3,57 \mathrm{aA}$ & $0,89 \mathrm{aA}$ \\
CV (\%) & 136,04 & & & 325,33 & \\
\hline
\end{tabular}

Médias seguidas de letras diferentes maiúsculas nas colunas e minúsculas nas linhas diferem $(P<0,05)$ pelo teste Tukey.

$\mathrm{NC}=25$ e $50 \%$ de concentrado na MS

$\mathrm{CS}=$ condição sexual; $\mathrm{F}=$ fêmea; $\mathrm{MC}=$ macho castrado; $\mathrm{MNC}=$ macho não-castrado.

de novilhos e não observaram diferença para a digestibilidade ruminal do EE, que foi, em média, -3,52\% versus $12,72 \%$ deste trabalho.

Os teores médios de MS variaram de 82,94 a 77,24\% e foram inferiores aos relatados por Ladeira et al. (1999b), de 90,3\%, e Valadares Filho (1995), de 89,2\%, em revisão de dados da literatura nacional. No entanto, foram próximos ao observado por Dias (2005), de 80,44\%. Os valores de MO obtidos neste trabalho (82,46 a 79,97\%) foram inferiores ao observado por Valadares (1997) - média de 89,13\% - e Valadares Filho (1995), 89,20\%, mas superiores ao obtido por Dias (2005), de 72,87\%. Os valores de $\mathrm{N}$ total foram próximos $(7,39$ e 6,91) aos observados na mesma literatura citada anteriormente. Os valores de N-RNA deste trabalho foram menores que os obtidos por Dias (2005), de 2,40\%, e próximos aos observados por Leão et al. (2004), cuja média foi de 1,8\%. A relação N-RNA:N-total foi semelhante à observada por Leão et al. (2004), média de $24,3 \%$.

Não houve efeito da interação $(\mathrm{P}>0,05)$ de NC e CS para o fluxo dos nutrientes e as eficiências microbianas expressas de diferentes formas (Tabela 7). A condição sexual influenciou $(\mathrm{P}<0,05)$ a eficiência microbiana, expressa em g de $\mathrm{Nmic} / \mathrm{kg}$ MODR, uma vez que a maior média foi obtida nos machos castrados.

O fluxo de MS microbiana foi, em média, de 1.160,37 g/ dia, superior à média de 635,27 g/dia observada por Dias et al. (2000), que não verificaram diferença na MS microbiana quando alteraram os níveis dietéticos de concentrado.

Hoover \& Stokes (1991), em revisão sobre a produção ótima de proteína microbiana em função do balanço de carboidratos e proteína, afirmaram que a taxa de turnover do conteúdo ruminal pode ser alterada por fatores como o nível de consumo, a proporção de volumoso na dieta, o tamanho de partículas, a temperatura ambiente e os sais minerais, entre outros, portanto, é difícil separar os efeitos
Tabela 6 - Composição média das bactérias isoladas do rúmen Nível de concentrado (\%)

\begin{tabular}{lrr}
\cline { 2 - 3 } Item & \multicolumn{1}{c}{25} & \multicolumn{1}{c}{50} \\
\hline MS (\%) & 82,94 & 77,24 \\
MO $^{1}$ & 82,46 & 79,97 \\
N-total $^{1}$ & 7,39 & 6,91 \\
N-RNA $^{1}$ & 1,81 & 1,77 \\
N-RNA:N-Total $^{1}$ & 24,40 & 25,61 \\
\hline
\end{tabular}

$\mathrm{N}-\mathrm{RNA}=\mathrm{N}$ do ácido ribonucléico

1 Porcentagem na MS.

nutricionais dos fisiológicos. Ladeira et al. (1999a) e Cardoso et al. (2000) obtiveram aumento da MS mic, pois maiores consumos das dietas foram observados com o acréscimo nos níveis de concentrado.

A eficiência microbiana expressa em gNmic/kgMODR foi maior $(\mathrm{P}<0,05)$ para machos castrados (Tabela 7$)$. De acordo com Owens \& Goetsch (1986), a produção de N microbiano geralmente aumenta quando ocorre maior consumo de MS. Neste estudo, embora não tenha sido observada diferença significativa para os consumos, os animais castrados, em geral, apresentaram as maiores médias, cujos consumos de MS e MO foram aproximadamente 13 unidades percentuais maiores que os demais (Tabela 3).

Como mencionado, o aumento dos níveis de concentrado na dieta não acarretou aumento na quantidade de MODR e MOVDR e, conseqüentemente, não influenciou a produção microbiana, expressa em gPBmic/kgNDT, gNmic/kgMODR e gNmic/kgMOVDR. Ladeira et al. (1999a, b) verificaram aumento nas quantidades de MODR e CHODR quando elevaram os níveis de concentrado nas rações, tendo observado para MODR valores médios de 1,97 a 3,11 kg/dia com 37,5 e $62,5 \%$ de concentrado, respectivamente, em comparação às médias de 1,66 a 1,73 kg/ dia de MODR deste estudo. Da mesma forma, Cardoso et al. (2000) e Dias et al. (2000) obtiveram aumentos lineares da MODR e CHODR com o incremento dos níveis de concentrado. Esses autores concluíram que o efeito linear observado para o aumento quantitativo desses nutrientes pode estar associado à adequada quantidade de proteína e energia disponível no rúmen para o crescimento microbiano.

O NRC (1996) aponta o consumo de PDR e o tipo de carboidrato (estrutural ou não-estrutural), além da taxa de passagem, como os principais fatores que afetam a síntese de proteína microbiana, enquanto Hoover \& Stokes (1991), Meng et al. (1999) e Dewhurst et al. (2000) descreveram sobre a importância da sincronia de degradação da proteína e da fonte de carboidrato. 
Tabela 7 - Fluxo de nutrientes e da eficiência microbiana em bovinos de três condições sexuais (CS) alimentados com dietas contendo 25 ou $50 \%$ de concentrado

\begin{tabular}{|c|c|c|c|c|c|c|c|c|c|}
\hline Item & \multicolumn{2}{|c|}{ Nível de concentrado (\%) } & \multicolumn{3}{|c|}{ Condição sexual (CS) } & \multicolumn{3}{|c|}{ Valor P } & CV (\%) \\
\hline \multicolumn{10}{|c|}{ Fluxo de nutrientes } \\
\hline $\mathrm{N} \operatorname{mic}^{1}$ & 82,9 & 80,8 & 72,0 & 95,3 & 78,4 & 0,872 & 0,336 & 0,767 & 35,1 \\
\hline PB mic ${ }^{1}$ & 518,3 & 505,2 & 450,0 & 595,4 & 489,9 & 0,872 & 0,334 & 0,767 & 35,1 \\
\hline MS mic ${ }^{1}$ & $1.143,6$ & $1.177,1$ & $1.021,9$ & $1.393,8$ & $1.065,3$ & 0,868 & 0,283 & 0,754 & 38,2 \\
\hline MO mic ${ }^{1}$ & 936,9 & 941,3 & 839,9 & $1.100,6$ & 876,8 & 0,979 & 0,396 & 0,764 & 38,7 \\
\hline $\operatorname{MODR}^{2,3}$ & 1,66 & 1,73 & 1,63 & 1,46 & 1,99 & 0,827 & 0,420 & 0,872 & 40,9 \\
\hline $\operatorname{MOVDR}^{2,4}$ & 2,60 & 2,67 & 2,47 & 2,56 & 2,87 & 0,857 & 0,701 & 0,941 & 33,9 \\
\hline PBmic/kgNDT ${ }^{1}$ & 184,37 & 192,05 & 176,16 & 197,95 & 190,52 & 0,702 & 0,628 & 0,513 & 19,4 \\
\hline $\mathrm{Nmic}_{\text {kgMODR }}{ }^{1}$ & 44,19 & 47,38 & $43,34 b$ & $57,32 \mathrm{a}$ & $36,69 b$ & 0,508 & 0,016 & 0,322 & 21,0 \\
\hline Nmic/kgMOVDR $^{1}$ & 33,56 & 30,24 & 28,80 & 36,96 & 29,95 & 0,368 & 0,171 & 0,464 & 25,0 \\
\hline
\end{tabular}

${ }^{1} \mathrm{~g} / \mathrm{dia} ;{ }^{2} \mathrm{~kg} / \mathrm{dia} ;{ }^{3} \mathrm{MODR}=\mathrm{MO}$ degradada no rúmen; ${ }^{4} \mathrm{MOVDR}=\mathrm{MO}$ verdadeiramente degradada no rúmen.

$\mathrm{NC}=$ nível de concentrado (25 ou 50\% na MS); CS = condição sexual; F = fêmea; $\mathrm{MC}$ = macho castrado; MNC = macho não-castrado.

$\mathrm{P}=$ probabilidade; $\mathrm{NC}^{*} \mathrm{CS}=$ nível de concentrado $\times$ condição sexual.

Quando expressa na forma utilizada pelo NRC (1996), ou seja, em função da concentração de NDT, a eficiência microbiana média encontrada neste trabalho foi de 188,2 g PBmic/kgNDT ou 18,82 g PBmic/100 gNDT, superior à adotada pelo NRC (2001), de 13 g PBmic/100 gNDT.

$\mathrm{O} \mathrm{pH}$ foi influenciado $(\mathrm{P}<0,001)$ pelos níveis de concentrado (NC) e tempos de coleta (T) (Figura 1). Entre os níveis de concentrado e horários, os valores de $\mathrm{pH}$ variaram de 6,6 a 6,8 e de 6,4 a 7,3, para os níveis de 25 e 50\% de concentrado, respectivamente, cujos dados se ajustaram ao efeito quadrático: $\hat{\mathrm{Y}}=6,1517+0,25317 * \mathrm{~T}-0,01517 *\left(\mathrm{~T}^{\wedge} 2\right)+$ $0,02365 * \mathrm{NC}-0,01293 * \mathrm{~T} * \mathrm{NC}+0,00112 *\left(\mathrm{~T}^{\wedge} 2\right) * \mathrm{NC} ; \mathrm{r}^{2}=0,98$.

Nos animais alimentados com $50 \%$ de concentrado, ocorreu diminuição do pH ruminal imediatamente antes da alimentação até 4 horas após alimentação. De acordo com Van Soest (1994), a atividade de bactérias celulolíticas

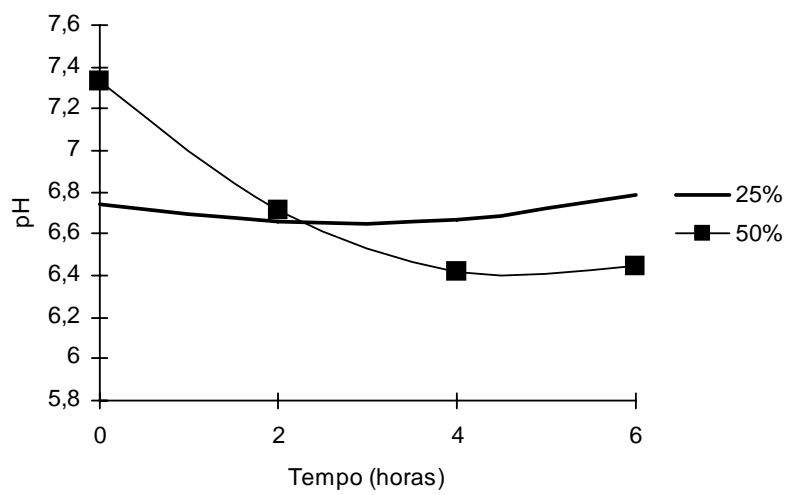

Figura 1 - Estimativa do $\mathrm{pH}$ do líquido ruminal em bovinos de três condições sexuais (CS) alimentados com dietas com 25 ou $50 \%$ de concentrado. pode diminuir em pH menor que 6,0. Cecava et al. (1991) e Dias et al. (2000) também verificaram redução do pH ruminal com o aumento dos níveis de concentrado.

$\mathrm{O}$ modelo que melhor se ajustou à concentração de $\mathrm{N}-\mathrm{NH}_{3}$, expressa em mg N-NH $\mathrm{NH}_{3} / 100 \mathrm{~mL}$ de líquido ruminal, foi $\hat{\mathrm{Y}}=5,74857+10,75369 * \mathrm{~T}-3.86917 *\left(\mathrm{~T}^{\wedge} 2\right)+0,33997 *\left(\mathrm{~T}^{\wedge} 3\right)$ $\left(\mathrm{R}^{2}=0,9618\right)$, em que T representa o tempo após alimentação (Figura 2).

As concentrações de $\mathrm{N}-\mathrm{NH}_{3}$ foram influenciadas cubicamente pelos tempos de coleta e a concentração máxima, estimada em 14,55 mg N-NH$/ 100 \mathrm{~mL}$, foi obtida 1,83 hora após o fornecimento das dietas. Ladeira et al. (1999 a), Dias et al. (2000) e Cardoso et al. (2000) obtiveram efeito quadrático, talvez por terem usado maiores quantidades de concentrado nas dietas experimentais. Dias et al. (2000) observaram concentração de $\mathrm{N}-\mathrm{NH}_{3}$ de 18,47 mg N-NH$/$

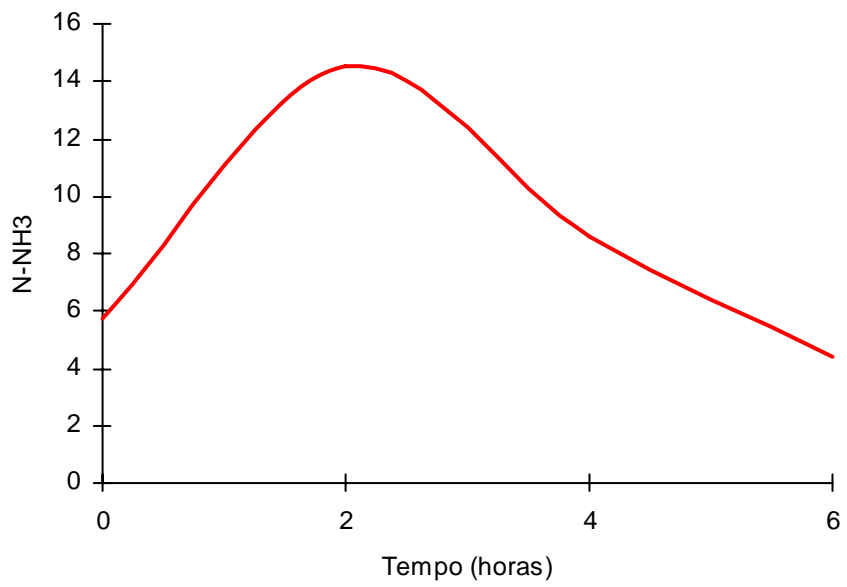

Figura 2 - Estimativa da concentração de amônia do líquido ruminal em bovinos de três condições sexuais (CS) alimentados com dietas com 25 ou $50 \%$ de concentrado. 
$100 \mathrm{~mL} 2,0$ horas após o fornecimento das dietas com o nível de $50 \%$ de concentrado. O menor resultado observado neste estudo possivelmente se deve ao fato de as dietas terem sido isoprotéicas (Tabela 2) e à melhor sincronia na degradação da proteína com a fermentação dos carboidratos.

\section{Conclusões}

O aumento dos níveis de concentrado na dieta não promoveu respostas positivas nos consumos, nas digestibilidades parcial e total da maioria dos nutrientes e na produção microbiana. As concentrações de amônia do líquido ruminal máximas de $14,55 \mathrm{mg} / \mathrm{dL}$ foram estimadas 1,83 hora após alimentação. Não houve efeito da condição sexual sobre a maioria das variáveis avaliadas.

\section{Agradecimento}

À professora Rilene Ferreira Diniz Valadares, pelo auxílio durante a coleta de urina.

Aos estagiários Danielle, João Paulo, Mozart e Cláudia, pelo auxílio na condução do experimento.

\section{Literatura Citada}

ANUAlPeC 2005. Anuário da Pecuária Brasileira: FNP Consultoria \& Comércio, 2005. 400p.

BARbosA, A.M. Período de coleta de urina e de fezes para avaliação da excreção de creatinina, produção microbiana e digestibilidade aparente dos nutrientes em Nelore. Viçosa, MG: Universidade Federal de Viçosa, 2005. 63p. Dissertação (Mestrado em Medicina Veterinária) - Universidade Federal de Viçosa, 2005.

BRANCO, A.F.; HARMON, D.L.; BOHNERT, D.W. et al. Estimating true digestibility of nonstructural carbohydrates in the small intestine of steers. Journal of Animal Science, v.77, p.18891895, 1999.

CARDOSO, R.C.; VALADARES FILHO, S.C.; COELHO DA SILVA, J.F. et al. Síntese microbiana, pH e concentração de amônia ruminal e balanço de compostos nitrogenados, em novilhos $F_{1}$ Limousin x Nelore. Revista Brasileira de Zootecnia, v.29, n.6, p.1844-1852, 2000.

CAVALCANTE, M.A.B.; PEREIRA, O.G.; VALADARES FILHO, S.C. et al. Níveis de proteína bruta em dietas para bovinos de corte: consumo, digestibilidade total e desempenho produtivo. Revista Brasileira de Zootecnia, v.34, n.3, p.711-719, 2005a.

CAVALCANTE, M.A.B.; PEREIRA, O.G.; VALADARES FILHO, S.C. et al. Níveis de proteína bruta em dietas para bovinos de corte: consumo e digestibilidades total e parcial dos nutrientes. Revista Brasileira de Zootecnia, v.34, n.6, p.2200-2208, 2005b (supl.).

CECAVA, M.J.; MERCHEN, N.R.; GAY, L.C. et al. Composition of ruminal bacteria harvest from steers as influenced by dietary energy level, feeding frequency, and isolation techniques. Journal of Dairy Science, v.73, p.2480-2488, 1990.

CECAVA, M.J.; MERCHEN, N.R.; BERGER, L.L. Effects of dietary energy level and protein source on nutrient digestion and ruminal nitrogen metabolism in steers. Journal of Animal Science, v.69, p.2230-2243, 1991.
CHIZZOTTI, M.L.; VALADARES FILHO, S.C.; LEÃO, M.I. et al. Casca de algodão em substituição parcial à silagem de capimelefante para novilhos. 1. Consumo, degradabilidade e digestibilidade total e parcial. Revista Brasileira de Zootecnia, v.34, p.2093-2102, 2005.

DEWHURST, R.J.; DAVIES, D.R.; MERRY, R.J. Microbial protein supply from the rumen. Animal Feed Science and Technology, v.85, p.1-21, 2000.

DIAS, H.L.C.; VALADARES FILHO, S.C.; COELHO DA SILVA, J.F. et al. Consumo e digestão totais e parciais em novilhos $F_{1}$ Limousin $\mathrm{x}$ Nelore alimentados com dietas contendo cinco níveis de concentrado. Revista Brasileira de Zootecnia, v.29, p.545-554, 2000.

DIAS, M. Técnicas para estimativa de parâmetros de digestibilidade e produção microbiana em bovinos. Viçosa, MG: Universidade Federal de Viçosa, 2003. 105p. Dissertação (Mestrado em Zootecnia) - Universidade Federal de Viçosa, 2005.

FRANCO, A.V.M.; FRANCO, G.L.; ANDRADE, P. Parâmetros ruminais e desaparecimento da MS, PB e FDN da forragem em bovinos suplementados em pastagem na estação seca. Revista Brasileira de Zootecnia, v.33, p.1316-1324, 2004.

HALL, M.B. Calculation of non-structural carbohydrate content of feeds that contain non-protein nitrogen. Florida: University of Florida, 2000. p.A-25 (Bulletin, 339).

HOOVER, W.H.; STOKES, S.R. Balancing carbohydrates and proteins for optimum rumen microbial yield. Journal of Dairy Science, v.74, p.3630-3644, 1991.

ÍTAVO, L.C.V.; VALADARES FILHO, S.C.; SILVA, F.F. et al. Consumo e digestibilidades aparentes totais e parciais de nutrientes em novilhos alimentados com dietas contendo vários níveis de concentrado. Revista Brasileira de Zootecnia, v.31, p.1543-1552, 2002.

KOZLOSKI, G.V. Bioquímica dos ruminantes. 1.ed. Santa Maria: Universidade Federal de Santa Maria, 2002. 140p.

LACÔRTE, A.J.F. Principais aspectos do confinamento de gado de corte no Brasil. In: SIMPÓSIO DE PECUÁRIA DE CORTE: NOVOS CONCEITOS NA PRODUÇÃO BOVINA, 2., 2002, Lavras. Anais... Lavras: Universidade Federal de Lavras, 2002. p.302.

LADEIRA, M.M.; VALADARES FILHO, S.C.; LEÃO, M.I. et al. Consumo e digestibilidades aparentes totais e parciais de dietas contendo diferentes níveis de concentrado, em novilhos Nelore. Revista Brasileira de Zootecnia, v.28, p.395-403, 1999a.

LADEIRA, M.M.; VALADARES FILHO, S.C.; LEÃO, M.I. et al. Eficiência microbiana, concentração de amônia e pH ruminal e perdas nitrogenadas endógenas, em novilhos Nelore. Revista Brasileira de Zootecnia, v.28, p.404-411, 1999b.

LEÃO, M.I.; VALADARES FILHO, S.C.; RENNÓ, L.N. et al. Consumos e digestibilidades totais e parciais de matéria seca, matéria orgânica, proteína bruta e extrato etéreo em novilhos submetidos a três níveis de ingestão e duas metodologias de coleta de digestas abomasal e omasal. Revista Brasileira de Zootecnia, v.33, p.1604-1615, 2004.

LEÃO, M.I.; VALADARES FILHO, S.C.; RENNÓ, L.N. et al. Consumos e digestibilidades totais e parciais de carboidratos totais, fibra em detergente neutro e carboidratos não-fibrosos em novilhos submetidos a três níveis de ingestão e duas metodologias de coleta de digestas abomasal e omasal. Revista Brasileira de Zootecnia, v.34, p.670-678, 2005.

MENDES, A.R.; EZEQUIEL, J.M.B.; GALATI, R.L. et al. Consumo e digestibilidades total e parcial de dietas utilizando farelo de girassol e três fontes de energia em novilhos confinados. Revista Brasileira de Zootecnia, v.34, p.679-691, 2005.

MENG, Q.; KERLEY, M.S.; LUDDEN, P.A. et al. Fermentation substrate and dilution rate interact to affect microbial growth and efficiency. Journal of Animal Science, v.77, p.206-214, 1999.

MERTENS, D.R. Analysis of fiber in feeds and its use in feed evaluation and ration formulation. In: SIMPÓSIO INTERNACIONAL DE 
RUMINANTES, 1992, Lavras. Anais... Lavras: Universidade Federal de Lavras, 1992. p.381.

NATIONAL RESEARCH COUNCIL - NRC. Nutrient requirements of beef cattle. 7.ed. Washington, D.C.: National Academy Press, 1996. 242p.

NATIONAL RESEARCH COUNCIL - NRC. Nutrient requirements of dairy cattle. 7.ed. Washington, D.C: National Academy Press, 2001. 381p.

NOCEK, J.E.; RUSSEL, J.B. Protein and energy as na integrated system. Relationship of ruminal protein and carbohydrate availability to microbial synthesis and milk production. Journal of Dairy Science, v.71, p.2070-2107, 1988.

OWENS, F.N.; GOETSCH, A.L. Digest passage and microbial protein synthesis. In: MILLIGAN L.P.; GROVUM, W.L.; DOBSON, A. (Eds). Control of digestion and metabolism in ruminants. Prentice Hall, 1986. p.196-226.

RENNÓ, L.N. Consumo, digestibilidades total e parcial, produção microbiana, parâmetros ruminais e excreções de uréia e creatinina em novilhos alimentados com dietas contendo quatro níveis de uréia ou dois níveis de proteína. Viçosa, MG: Universidade Federal de Viçosa, 2003. 252p. Tese (Doutorado em Zootecnia) - Universidade Federal de Viçosa, 2003.

RIBEIRO, K.G.; GARCIA, R.; PEREIRA, O.G. et al. Eficiência microbiana, fluxo de compostos nitrogenados no abomaso, amônia e $\mathrm{pH}$ ruminais, em bovinos recebendo dietas contendo feno de capim-Tifton 85 de diferentes idades de rebrota. Revista Brasileira de Zootecnia, v.30, p.581-588, 2001.

SATTER, L.D.; SLYTER, L.L. Effect of ammonia concentration on rumen microbial protein production in vitro. British Journal of Nutrition, v.32, p.199-208, 1974

STATISTICAL ANALYSES SYSTEM - SAS. SAS/STAT user's guide (Release 8.0), Cary: SAS Institute, 1999. (CD-ROM).

SILVA, D.J.; QUEIROZ, A.C. Análises de alimentos: métodos químicos e biológicos. 3.ed. Viçosa, MG: Universidade Federal de Viçosa, 2002. 235p.
UNIVERSIDADE FEDERAL DE VIÇOSA - UFV. Departamento de Engenharia Agrícola. Estação Meteorológica. Viçosa, MG: 2006. n.p.

USHIDA, K.; LASSALAS, B.; JOUANY, J.P. Determination of assay parameters for RNA analysis in bacterial and duodenal samples by spectrophotometry. Influence of sample treatment and preservation. Reproduction, Nutrition and Development, v.25, p.1037-1046, 1985.

VALADARES, R.F.D. Níveis de proteína em dietas de bovinos: consumo, digestibilidade, eficiência microbiana, amônia ruminal, uréia plasmática e excreções de uréia e creatinina. Belo Horizonte: Universidade Federal de Minas Gerais, 1997. 103p. Tese (Doutorado em Ciência Animal) Universidade Federal de Minas Gerais, 1997.

VALADARES, R.F.D.; VALADARES FILHO, S.C.; GONÇALVES, L.C. et al. Níveis de proteína em dietas de bovinos. 4. Concentrações de amônia ruminal e uréia plasmática e excreções de uréia e creatinina. Revista Brasileira de Zootecnia, v.26, p.1270-1278, 1997.

VALADARES FILHO, S.C. Eficiência de síntese de proteína microbiana, degradação ruminal e digestibilidade intestinal da proteína bruta, em bovinos. In: SIMPÓSIO INTERNATIONAL SOBRE EXIGÊNCIAS NUTRICIONAIS DE RUMINANTES 1995, Viçosa, MG. Anais... Viçosa, MG: Universidade Federal de Viçosa, 1995. p.355-388.

Van SOEST, P.J.; ROBERTSON, J.B. Analysis of forages and fibrous foods. Ithaca: Cornell University, 1985. 202p.

Van SOEST, P.J. Nutritional ecology of the ruminant. 2.ed. London: Comstock Publishing Associates, 1994. 476p.

ZINN, R.A.; OWENS, F.N. Influence of feed intake level on site of digestion in steers fed a high concentrate diet. Journal of Animal Science, v.56, p.471-475, 1983.

WILLIANS, C.H.; DAVID, D.J.; IISMA, O. The determination of chromic oxide in faeces samples by atomic absorption spectrophotometry. Journal of Agricultural Science, v.59, p.381-385, 1962. 